\title{
A doença na ópera*
}

\author{
João Paulo André \\ Departamento/Centro de Química, Escola de Ciências da Universidade do Minho, Braga \\ jandre@quimica.uminho.pt
}

\begin{abstract}
Diseases in Opera - Over a time period of four centuries, opera has bequeathed a portrait of western society which is an important contribution to a better understanding of history and to our perception of diseases and their various protagonists throughout the ages.
\end{abstract}

Ao longo de quatro séculos, a ópera legou-nos um retrato da sociedade ocidental que constitui um valioso instrumento para o conhecimento da História e da forma como a doença e os seus intervenientes têm sido encarados em diferentes épocas.

\section{Introdução}

A ópera nasceu em Florença, em 1597, com a criação de Dafne por Jacopo Peri, tendo por base os padrões estéticos e artísticos da antiga tragédia grega. Quanto às doenças, essas são inerentes à Humanidade; as origens da medicina, por sua vez, perdem-se nas brumas do tempo. Vendo bem, poder-se-á afirmar que a doença está presente logo na primeira de todas as óperas, ainda que de forma subliminar: Eros dispara sobre Dafne uma seta de chumbo que a faz rejeitar as investidas de Apolo, que fora atingido por uma de ouro. Ora, como se sabe, o chumbo é um metal tóxico que provoca saturnismo, ou plumbismo.

Verdadeiro espelho da vida, e, por isso, também da morte, o reportório operático tornar-se-ia um repositório de doenças. Recentemente, uma análise efetuada a 493 óperas, datadas de 1777 a 2016, revelou que 53 (10,7\%) incluíam um paciente e/ou um médico como personagens [1].

\section{Médicos}

Comecemos pelos praticantes da nobre arte e ciência da medicina, que, diga-se em abono da verdade, os primeiros tempos de ópera não dignificaram excessivamente. De um modo geral, o personagem operático do médico não era para ser levado muito a sério, fazendo jus ao mordaz dito de Voltaire de que o médico não passava de alguém que administrava medicamentos de que pouco sabia a doentes cujos corpos conhecia ainda menos; ou, ainda, que a arte da medicina consistia em distrair o doente enquanto a natureza se encarregava de o curar. Assim, na ópera, o médico surgia como um personagem cómico, tipicamente do sexo masculino e cantado pelas vozes graves de um baixo ou de um barítono (vozes normalmente destinadas às figuras de autoridade, sobretudo a de baixo). Por vezes eram papéis meramente falados, ou até mesmo mudos.

As peças teatrais de Beaumarchais $O$ barbeiro de SeviIha e As bodas de Fígaro estiveram na origem de uma série de óperas inaugurada com O barbeiro de Sevilha (1776)

\footnotetext{
* Artigo baseado na palestra proferida na sessão de entrega do Prémio Ensino Professor Francisco Pulido Valente 2018, no dia 24 de maio de 2018, no Grande Auditório João Lobo Antunes da Faculdade de Medicina da Universidade de Lisboa.
}

do checo Antonín Benda. Seguir-se-iam outras versões, de que se destacaram as dos italianos Giovanni Paisiello (1782) e Gioachino Rossini (1816), tendo a deste último sido a que de forma definitiva se implantou no reportório. N'O barbeiro encontramos o Dr. Bartolo (Figura 1), médico de meia-idade cuja única intervenção profissional é quando o arguto Fígaro maquina uma febre escarlatina para D. Basílio. Das várias adaptações operáticas d’As bodas de Fígaro, entre elas a do nosso Marcos Portugal (1799), destacou-se de longe a de Mozart (1786). Nela, o Dr. Bartolo volta a comparecer, sobretudo para se vingar do barbeiro Fígaro, que lhe estragara os planos de casamento com Rosina.

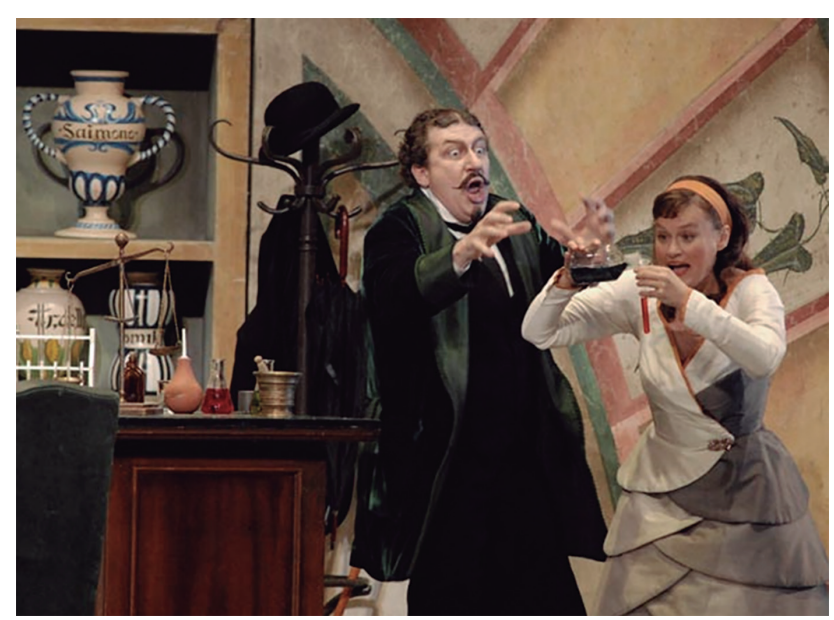

Figura 1 - Michael Eder (Bartolo) e Vesselina Kasarova (Rosina) em O barbeiro de Sevilha (Semperoper, Dresden, 2008).

Em Così fan tutte (1790), Mozart também parodiou uma certa medicina da época, concretamente a teoria do magnetismo animal (Figura 2), então defendida pelo médico alemão Franz Mesmer (1734-1815) - razão por que também ficou conhecida por mesmerismo. Tal ocorre quando a espertalhona criada Despina se disfarça de médico, fingindo tratar os dois falsos albaneses, que se dizem intoxicados com arsénio. Tudo isto para porem à prova a fidelidade das futuras esposas, a quem asseguram ficarem curados se delas receberem um beijo. 
A talho de foice, mencione-se que as práticas médicas de Mesmer em Paris foram, em 1784, alvo de uma averiguação por uma comissão que incluía figuras como o químico Antoine Lavoisier, o multifacetado norte-americano Benjamin Franklin (Figura 2) e o médico Joseph-Ignace Guillotin (a quem, erradamente, é atribuída a invenção da guilhotina mas que somente sugeriu a sua utilização, por causar menos dor a quem era executado). No seguimento dessa investigação, Mesmer foi proibido de exercer medicina em França.
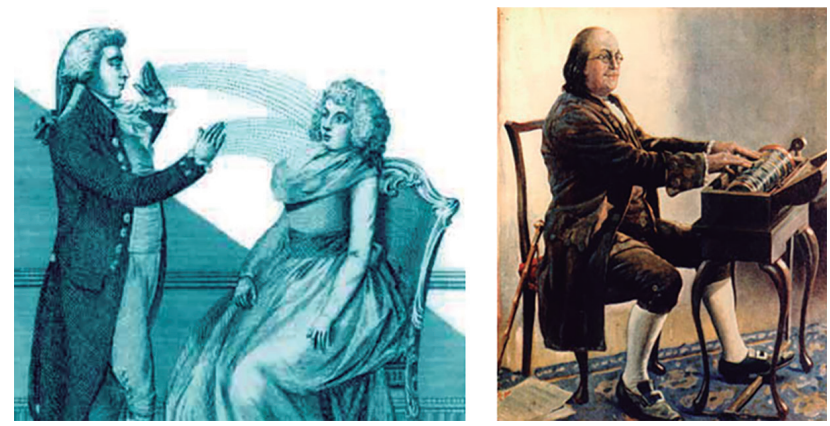

Figura 2 - Esquerda: Franz Mesmer numa das suas sessões terapêuticas de mesmerismo. Direita: Benjamin Franklin tocando a harmónica de vidro, por ele inventada.

Pese todo o descrédito do mesmerismo, este não deixou de exercer alguma influência na química, nomeadamente por associação ao vitalismo - a crença de os organismos vivos serem animados de uma força vital. Esta doutrina, defendida por químicos como Jacob Berzelius, teria no entanto os dias contados a partir do momento em que, em 1828, o alemão Friedrich Wöhler descreveu a síntese da ureia $\left(\mathrm{H}_{2} \mathrm{NCONH}_{2}\right)$ - que se pensava só poder ser produzida no corpo dos animais - a partir do composto inorgânico cianato de amónio $\left(\mathrm{NH}_{4}^{+} \mathrm{OCN}^{-}\right)$.

Entretanto, o modelo do médico burlesco continuou nas obras de outro mestre da ópera italiana, Gaetano Donizetti, das quais O elixir do amor (1832) e Don Pasquale (1843) são expoentes máximos. Trata-se de duas comédia de enganos, de amores e desamores, de heranças e deseranças, em que, na primeira, surge o médico ambulante, o Dr. Dulcamara (Figura 3), um simpático charlatão, e, na segunda, o Dr. Malatesta (“dor de cabeça”).

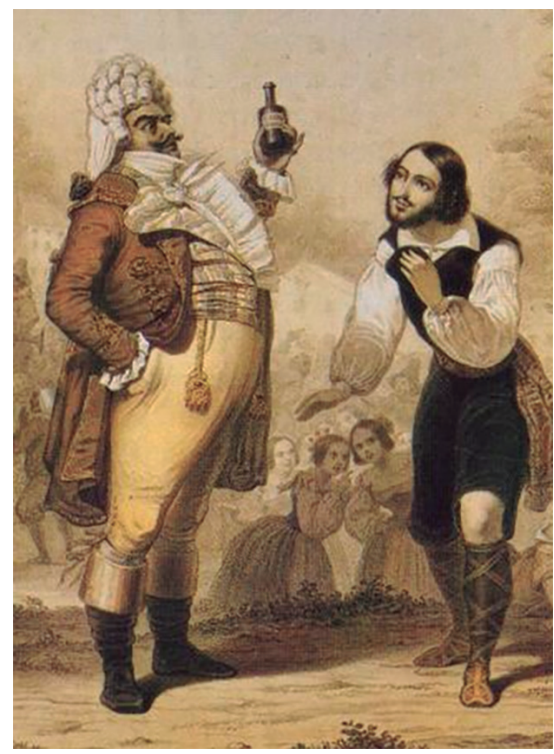

Figura 3 - O Dr. Dulcamara e o seu elixir do amor.
Na transição para a segunda metade do século XIX, o perfil do médico na ópera muda finalmente, graças, em grande parte, a Giuseppe Verdi. Assim, na sua Macbeth (1847), inspirada na tragédia homónima de Shakespeare, surge o personagem do médico (Figura 4), que, no entanto, é uma figura anónima que só intervém fugazmente nas cenas de alucinação e de sonambulismo de Lady Macbeth. Em La forza del destino (1862) temos outro médico, este com uma brevíssima intervenção vocal: trata-se de um cirurgião militar espanhol, chamado a tratar Don Alvaro, gravemente ferido em combate, removendo-lhe com sucesso uma bala do peito (Figura 5). Por sua vez, o médico de $L a$ traviata (1853), o Dr. Grenvil, está omnipresente ao longo de toda a ópera, podendo dizer-se com propriedade que é o verdadeiro médico de família. Trata-se no entanto de um médico muito dado à vida social, surgindo no primeiro e segundo atos em festas mundanas, bebendo e jogando. Por fim, no terceiro ato, quando Violetta está a morrer de tuberculose pulmonar, visita-a duas vezes no mesmo dia: a primeira pelas sete horas da manhã, e a segunda ao final da tarde, pouco antes dela se finar.

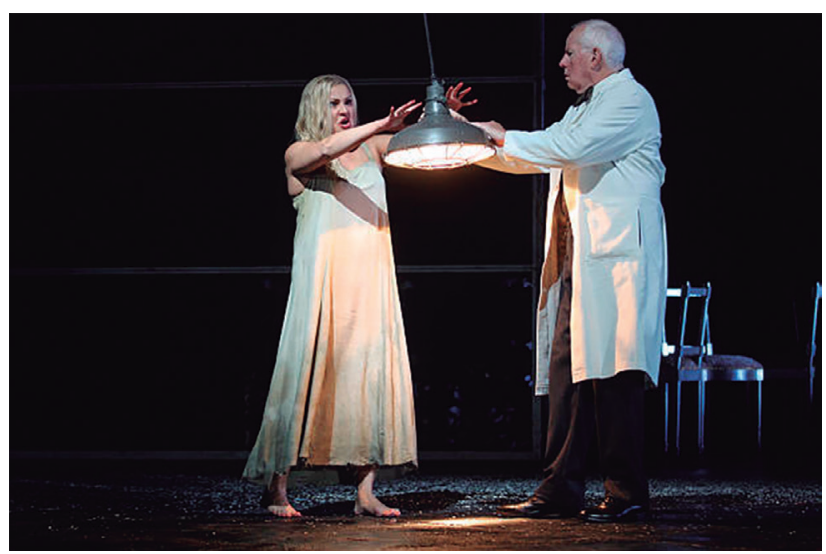

Figura 4 - Anna Netrebko (Lady Macbeth) e James Courtney (Médico) em Macbeth (MET, 2014).

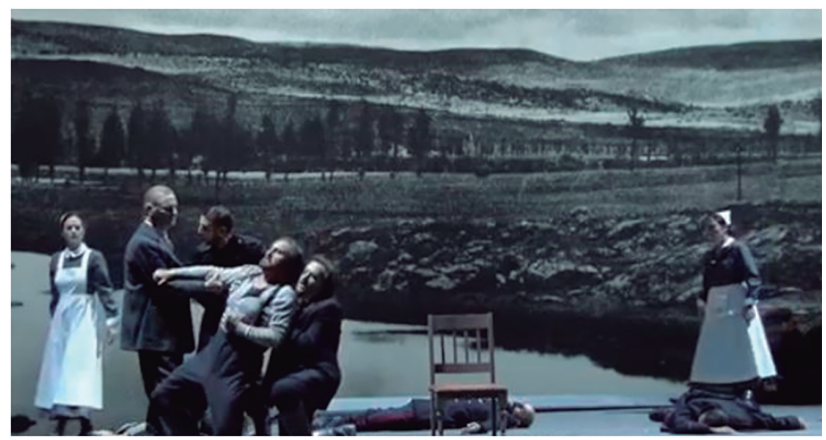

Figura 5 - La forza del destino (Dutch Opera, 2017).

Com o tempo, o reportório operático evoluiria de tal forma que é possível hoje catalogar as óperas por especialidade médica, praticamente da anestesiologia à urologia. Centremo-nos nalgumas!

A cardiologia, por exemplo, é expressa n' Os Contos d'Hoffmann (1881) de Jacques Offenbach, obra que já foi objeto de uma análise crítica por um cardiologista [2] e que também se destaca por introduzir a hereditariedade no palco lírico; já para não falar, obviamente, de Das Hertz ( $O$ coração, 1931) de Hans Pfitzner. No campo da neurologia, 
destacou-se há cerca de três décadas a ópera O Homem que confundiu a sua mulher com um chapéu (1986) de Michael Nyman, baseada num case study do neurologista Oliver Sacks.

Outro caso interessante é-nos apresentado na ópera $O$ nariz (1930) de Shostakovich, que relata a tragédia de um homem que um dia acorda sem o seu órgão olfativo. Se não se tratasse de uma ópera cómico-satírica que ridiculariza a sociedade, seríamos naturalmente levados a interrogar-nos por que não recorreu ele à cirurgia plástica. Bom, quanto a esta especialidade médica não haverá melhor exemplo do que a recente ópera Anna Nicole (2011) de Mark-Anthony Turnage, baseada na vida da playmate Anna Nicole Smith. Morta em 2007 na sequência de uma overdose, ficou lendária pelos seus peitos de silicone de tamanho XXXL. O cirurgião plástico na ópera chama-se Dr. Yes!

Atentemos agora em duas obras que exibem o rótulo da oftalmologia. Em Iolanta (1892) de Piotr Ilitch Tchaikovsky, surge o médico árabe, Ibn-Hakia, chamado a tratar a princesa Iolanta, que é cega de nascença mas que desconhece sê-lo (por ordem real nunca ninguém lho poderia revelar!). No monólogo “Dois mundos”, o médico expõe a ideia da interdependência da mente e do corpo, defendendo que o tratamento da princesa só será efetivo se ela souber que é cega. $\mathrm{O}$ rei recusa a terapia proposta para a filha mas uma súbita história de amor confere à princesa a visão. Refira-se ainda Die toten augen (Os olhos mortos, 1916) de Eugen d'Albert, ópera cuja ação decorre em tempos bíblicos, tendo como protagonista Myrtocle, também ela cega de nascença. A trama inclui um médico egípcio que não é bem-sucedido na cura da cegueira, embora a jovem acabe por obter a visão por intervenção divina.

Já em Fedora (1889), de Umberto Giordano, ópera do período do verismo em que surgem três médicos, os desenvolvimentos não são tão favoráveis. Logo no primeiro ato, em São Petersburgo, dois deles são chamados a socorrer o Conde Vladimir, ferido mortalmente com um tiro. O terceiro médico comparece no último ato, nos Alpes Suíços, também ele chamado em vão pois a protagonista ingerira veneno e a ação deste é rápida (Figura 6). (Poderia bem tratar-se de cianeto, mas o libreto não nos dá essa informação.)

Pese a seriedade com que o médico doravante passou a ser retratado na ópera, as comédias de enganos em torno de

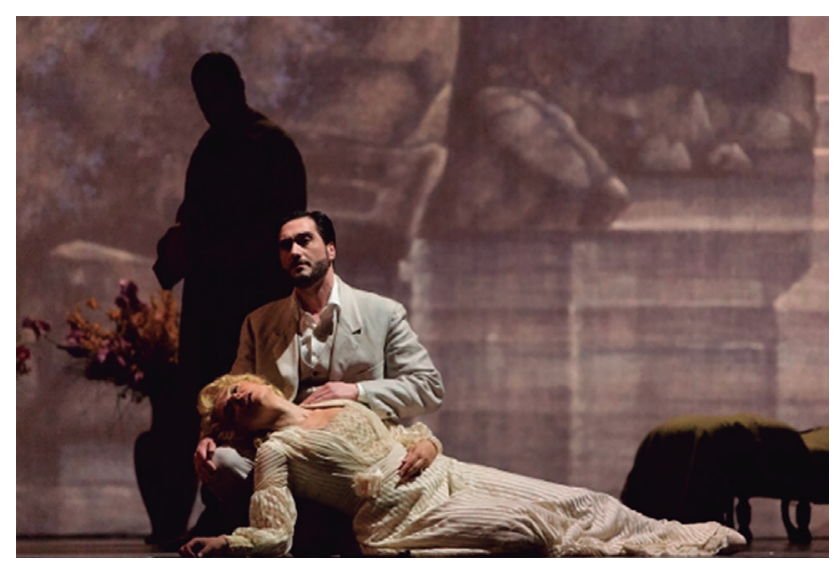

Figura 6 - Fiorenza Cedolins (Fedora) e Giuseppe Filianoti (Loris) em Fedora (Teatro San Carlo, Nápoles, 2016). médicos ou de imitantes seus jamais cessariam, sendo disso bons exemplos Le Docteur Miracle (1857), uma opereta de Georges Bizet, e Le Médecin malgré lui (1858), uma ópera cómica de Charles Gounod. A primeira, cuja ação gira em torno de um falso médico e de uma omelete supostamente envenenada, é célebre justamente pelo "quarteto da omelete". A segunda, que no III ato inclui a ária "Vive la médecine”, é baseada na farsa homónima de Molière em que um lenhador é obrigado a fazer-se passar por médico.

Merece um destaque especial L'amore medico (1913) de Ermanno Wolf-Ferrari, cuja trama envolve cinco médicos, quatro deles verdadeiros e um falso. Por sinal será este último o mais competente no diagnóstico e no tratamento da paciente. Ela é Lucinda, uma jovem que o pai mantém afastada de qualquer pretendente. A pobre moça entra em depressão e torna-se anoréxica. A finória criada Lisetta, percebendo tudo, convence o patrão de que a filha tem uma grave doença física. São então chamados quatro médicos. O primeiro diagnostica sanguinis ebollitio ("sangue em ebulição") - o que, em sentido figurado, não estaria muito longe da verdade - recomendando que seja sangrada. Para o segundo, o mal da jovem é "congestão gástrica”, pelo que lhe aconselha um emético. Já quanto ao terceiro, a doença é morbus inflammatio vaporum fumigatum (em poucas palavras: flatulência!), pelo que prescreve um laxante. Por fim, o quarto médico, que reconhece na jovem um problema de humorum cerebri glutinorum (algo como "lenta circulação cerebral”), recomenda um tónico. Após a partida dos médicos, Lisetta diz ao patrão que conhece outro ainda mais competente. Trata-se afinal de um garboso jovem que há muito trazia Lucinda debaixo de olho, e que insiste em ver a paciente a sós. Por fim, o pretenso médico diz ao pai da moça que nem todos os males são do corpo, que também podem ser do espírito, acrescentando que, no presente caso, tal só seria sanado com um casamento a fingir, e que ele próprio faria de noivo. E pronto, já se adivinha o final: Lucinda ficou curada e casada, e viveram todos felizes para sempre!

Em Gianni Schicchi (1918), de Giacomo Puccini, também encontramos um médico caricato e algo distraído, o Dr. Spinelloccio. Pensando que o velho Buoso Donati está ainda vivo, inadvertidamente acaba por permitir que o habilidoso Schicchi falsifique um testamento em favor próprio.

\section{Farmacêuticos}

Os farmacêuticos também cedo surgiram na Ópera, desde logo no seu habitat natural de trabalho. Tal aconteceu em 1768 com Der Apotheker (O farmacêutico) de Joseph Haydn, também conhecida como Lo speziale, na sua versão italiana (Figura 7). Trata-se de uma comédia baseada no quadrilátero amoroso constituído pelo velho farmacêutico Sempronio, o aprendiz de farmácia Mengone, o dandy Volpino e a jovem Grilleta. A ópera, que faz referência a múltiplos remédios para as mais diversas aplicações, inaugurou um estilo que seria continuado em Doktor und Apotheker (1786), do também austríaco Karl Ditters von Dittersdorf. O enredo desta centra-se na rivalidade entre o médico Dr. Krautmann (Ervanário) e o farmacêutico Stössel (Pilão). Embora se tratasse de um tipo de competição bastante comum no século XVIII, a situação neste caso é mais complexa, dado Leonore, filha do farmacêutico, estar 
apaixonada por Gotthold, filho do médico, no que é correspondida. Os dois rivais acabam por se reconciliar, a bem da felicidade dos jovens.

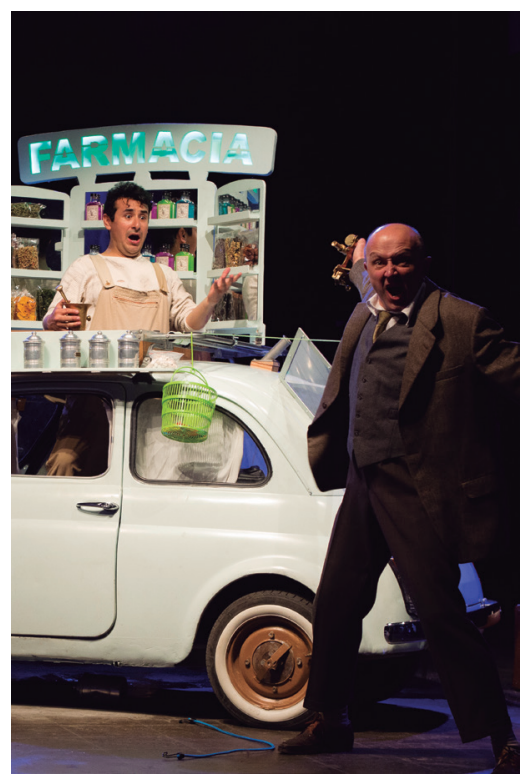

Figura 7 - Lo speziale (Teatro Nacional de Catalunya, 2018; (c) Judith Napjus).

Sinal dos tempos, quando estas óperas foram criadas começava a despontar a química moderna, dando-se o caso de alguns dos melhores químicos serem farmacêuticos. $\mathrm{O}$ exemplo mais significativo será o do sueco Carl Scheele, a quem ficou a dever-se a descoberta de nada mais, nada menos, do que sete elementos químicos, um deles o oxigénio - por sinal também descoberto quase em simultâneo por Joseph Pristley, em Inglaterra, e Antoine Lavoisier, em França.

Na linha destas óperas, já em pleno século XIX os irmãos Luigi e Federico Ricci compuseram Crispino e la comare (1850), cuja ação decorre parcialmente numa farmácia de Veneza. Nela é preparada a célebre teriaga (Figura 8), que se acreditava ser um antídoto para todos os venenos e cura para muitos males. O farmacêutico, Mirabolino, não é, porém, o personagem principal; este, sim, é Crispino, um pobre sapateiro analfabeto a quem aparece uma fada que o convence a dedicar-se à medicina, carreira em que acaba por ter sucesso graças aos poderes mágicos da sua inesperada protetora.
De qualquer modo, a ópera que melhor ilustra, embora de forma caricatural, o mundo da farmácia desse tempo é Il campanello (1836) de Donizetti, uma das joias do reportório buffo italiano. Don Annibale Pistacchio, um velho farmacêutico, casa com a jovem Serafina, para desespero do apaixonado desta, Enrico, que, para se vingar, vai arruinar-lhes a noite de núpcias. Ao longo da ópera, a campainha (campanello) da farmácia não para de tocar, sempre que Enrico, sob diferentes disfarces, vem aviar mais uma receita. E que receitas! Na ária “La Povera Anastasia”, enumera as infinitas maleitas da sua pretensa mulher Anastasia, dizendo que "é tísica, diabética, cega, paralítica, padece de migrena, tem asma, sete fístulas, dores de costas e ciática, assim como tumores na cabeça, já para não falar da gota e da artrite, que tanto a fazem sofrer”. De imediato entrega ao farmacêutico uma receita interminável, com os ingredientes mais inacreditáveis. Vários deles, apesar da sua elevada toxicidade (nomeadamente os compostos de metais pesados), tinham, em boa verdade, aplicação terapêutica naquela época.

Já no século XX, a figura do farmacêutico surge, por exemplo, na ópera Peter Grimes (1945) de Benjamin Britten. Trata-se de Ned Keene, o boticário de aldeia que fornece láudano (solução de ópio) à velha alcoviteira, a Sra. Sedley.

\section{Pacientes}

A primeira vez que a figura do doente surgiu de forma explícita na ópera terá, muito provavelmente, sido no drama burlesco l'Ospedale (ca. 1650), recentemente redescoberto. Trata-se de uma obra satírica de compositor anónimo, cuja trama envolve quatro pacientes que definham num hospital decadente, enquanto esperam a chegada do médico que alegadamente os curará. Um deles sofre de amor não correspondido, um outro de descontentamento profissional, outro ainda de neurose e o último de falta de dinheiro. O médico revelar-se-á ser o ministro da saúde, que, disfarçado, pretende investigar as condições de funcionamento do hospital.

Quanto a quadros clínicos específicos, o palco lírico tem sido local privilegiado para expressão das doenças mentais, as primeiras a entrar no reportório operático. Foi justamente em várias cenas ditas ‘de loucura’, que, nas primeiras décadas do século XIX, a ópera, dominada pelos padrões do Romantismo, alcançou alguns dos seus momentos
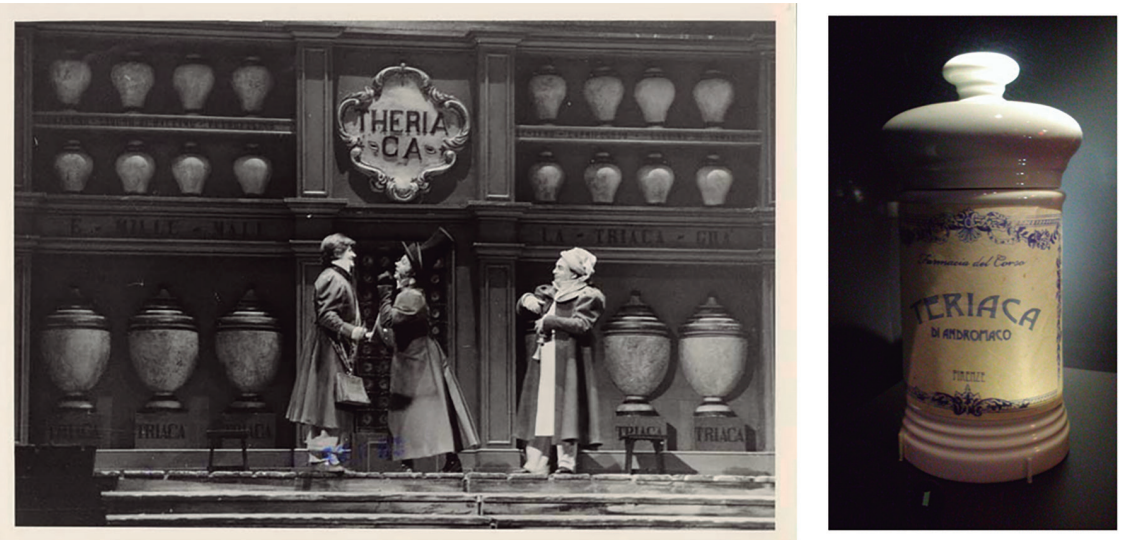

Figura 8 - Crispino e la Comare (Teatro La Fenice di Venezia, 1986) e frasco de farmácia destinado à teriaga. 
mais gloriosos. Não se tratava no entanto de uma novidade absoluta, pois em 1773, no II ato de Orlando (1773), Georg Friedrich Handel já concebera uma cena deste tipo: Orlando, cavaleiro de Carlos Magno, fica insano por amar a princesa Angelica, que ama outro homem. Outro exemplo precoce da demência no palco lírico foi Idomeneo (1781) de Mozart, que, no II ato, inclui a impressionante ária de Elletra "Oh smania! oh furie!”, a cujas risadas cortantes ninguém fica indiferente. Nina (1789), de Giovanni Paisiello, constitui outro marco importante na história da insanidade mental na ópera.

O grande mestre das 'cenas de loucura' no século XIX seria Donizetti, cuja ópera Lucia di Lammermoor (1835) constitui um dos exemplos mais notáveis (Figura 9). Lucia, fora de si, na noite de casamento assassina o marido, que não desejava: o seu amor era Edgardo. Inicialmente esta cena era acompanhada pelo som etéreo da harmónica de vidro, instrumento inventado por Benjamin Franklin em 1761 (Figura 2) e a que Franz Mesmer recorria nas suas terapias. Esta escolha de Donizetti não terá sido inocente, porquanto a harmónica é feita de cristal, um vidro que contém óxido de chumbo(II). Ora, é bem sabido que o chumbo é um metal que pode estar associado a algumas formas de demência. Por outro lado, a ‘cena de loucura' de Lucia di Lammermoor também poderá ser encarada, de forma metafórica, como um sinal de libertação tanto ao nível pessoal de Lucia como da psiquiatria enquanto especialidade médica. Com efeito, desde 1796, com a fundação da célebre instituição psiquiátrica The Retreat, em Iorque - onde os pacientes não eram amarrados -, que esta área da medicina se vinha a humanizar.

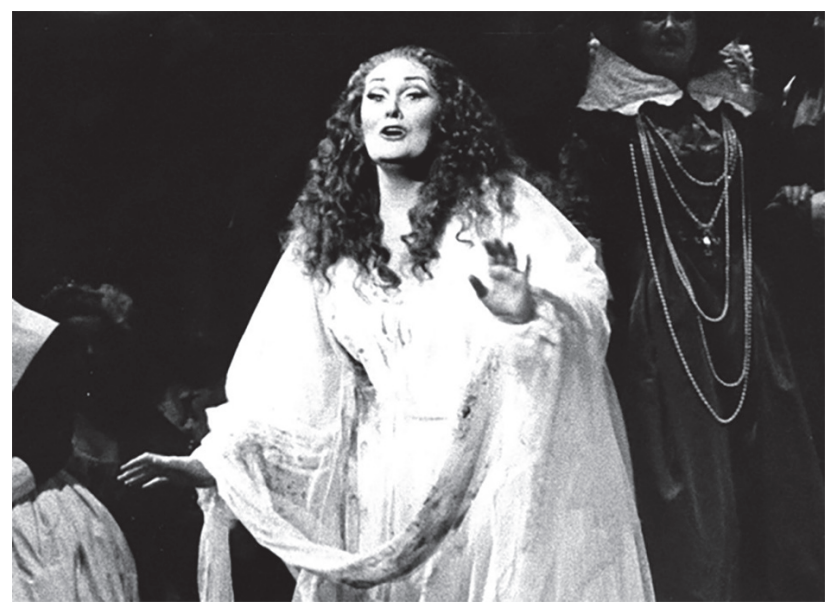

Figura 9 - Joan Sutherland na cena da loucura de Lucia di Lammermoor (c. 1980).

Apesar do já referido demérito de Franz Mesmer, por volta de 1820 as suas teorias foram parcialmente reabilitadas, por associação ao hipnotismo, ao sonambulismo e à demência, temáticas por que o público da época nutria grande interesse. O sonambulismo, em particular, tinha uma aura de mistério e magia a que os próprios médicos não eram indiferentes. Neste contexto não terá sido coincidência o aparecimento de La sonnambula de Bellini em 1831. O enredo desta ópera centra-se em Amina, noiva de Elvino, que numa crise de sonambulismo penetra nos aposentos de outro homem. O resto poder-se-á imaginar!... O ponto alto da ópera é a caminhada noturna de Amina sobre a altíssima ponte do moinho (Figura 10).

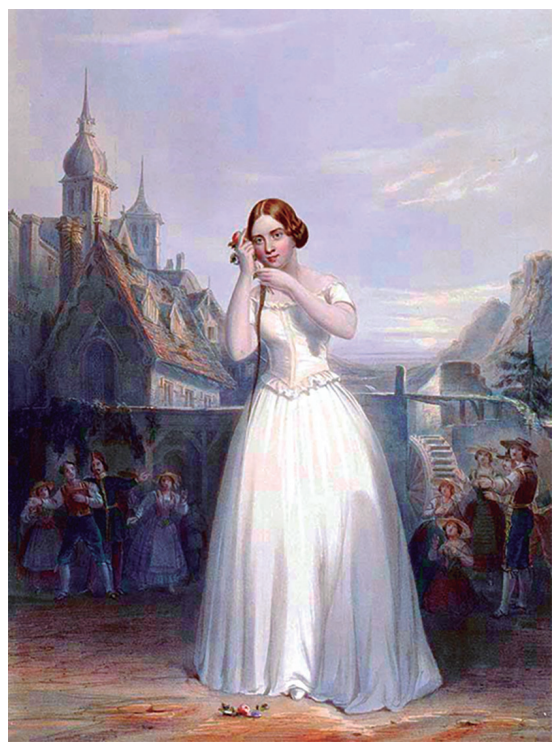

Figura 10 - Jenny Lind, o “rouxinol da Suécia”, em La Sonnambula.

Em 1847, quando Verdi estreia Macbeth, a temática do sonambulismo continuava na ordem do dia. Lady Macbeth, que instigara o marido a assassinar o rei Duncan, sofre de distúrbios do sono e vê constantemente sangue nas mãos. Em breve, porém, libretistas e compositores de ópera começariam a interessar-se por enredos envolvendo doenças do foro físico, em detrimento das do mental. Os tempos do Romantismo ficavam para trás, imperava agora o Realismo! De acordo com a nova tendência, uma das enfermidades que imediatamente passou para o palco foi a tuberculose pulmonar. Se no período do Romantismo esta chegara a ser idolatrada como ideal estético de morte, era agora pura e simplesmente um mal que grassava e a que ninguém estava imune. O interesse operático pela tuberculose acabou por coincidir temporalmente com alguns dos marcos históricos da sua investigação: em 1865 o francês Jean-Antoine Villemin demonstraria que se tratava de uma doença infeciosa, o que seria definitivamente provado em 1882 por Robert Koch, ao identificar o bacilo que adquiriria o seu nome. Foi neste contexto que, em 1853, surgiu $L a$ traviata (Figura 11), chocando muita gente e não obtendo sucesso: mostrava a realidade de forma demasiado crua. Já mais tarde, em 1896, destacou-se La bohème de Puccini (Figura 12), e, logo no ano seguinte, a réplica homónima de Leoncavallo.

Aproveite-se esta ocasião para recordar que o Professor Francisco Pulido Valente se dedicou à investigação desta doença. Destaque-se, por exemplo, a sua lição “As modernas ideias na patologia da tuberculose pulmonar”, proferida em 1925 no âmbito das comemorações do $1^{\circ}$ centenário da Escola Médico-Cirúrgica de Lisboa. Nesse mesmo ano deslocara-se em comissão de serviço a Copenhaga, para participar num congresso sobre um novo tratamento da doença, preconizado pelo dinamarquês Holger Møllgaard, baseado no uso da sanocrisina (tiossulfato duplo de ouro e sódio).

O distinto médico e professor dedicou-se igualmente ao estudo da sífilis, outra terrível enfermidade que a ópera 


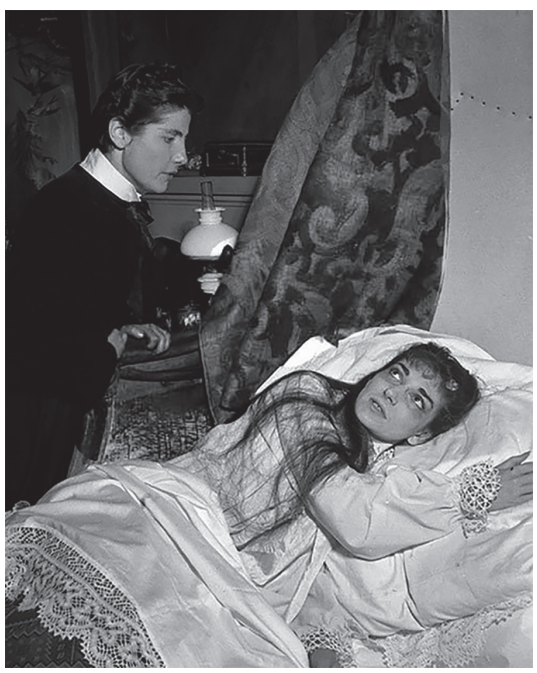

Figura 11 - Maria Callas (Violetta) e Luisa Mandelli (Annina) em La traviata (La Scala, 1955).

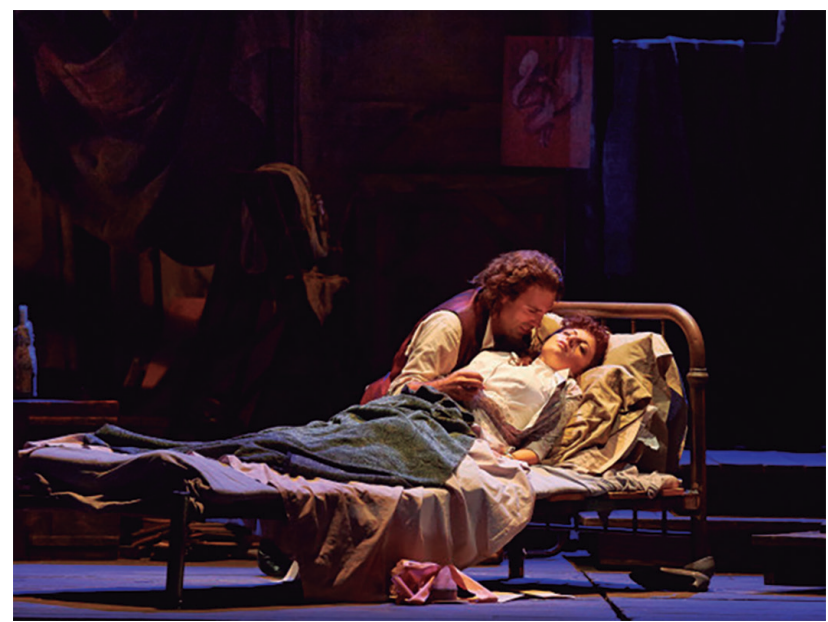

Figura 12 - Grazia Doronzio (Mimì) e Dimitri Pittas (Rodolfo) em La bohème (Canadian Opera Company, 2013).

não deixou de espelhar. Um dos exemplos operáticos mais fascinantes poderá ser encontrado em Parsifal (1882) de Richard Wagner, mesmo que os efeitos da treponema pallidum, a espiroqueta, nela compareçam de forma velada. Trata-se da história do puro Parsifal, redentor do pecador Amfortas, guardador do Santo Graal, que não resistira às tentações carnais de Kundry. Para guardar o cálice divino, Amfortas possuía a lança que ferira Jesus na cruz, mas bastou largá-la por uns instantes para que o seu inimigo Klingsor se apoderasse dela e lhe desferisse um golpe. A cura da ferida só seria possível através da ação milagrosa da mesma arma que a provocara, agora na posse do maligno Klingsor. A partir desse dia, Amfortas entra num grande sofrimento.

Esta obra de Wagner pode ter muitas leituras, sendo a mais óbvia a de inspiração cristã, havendo também quem reconheça nela o pensamento filosófico de Schopenhauer, que defendia que a única via para o Homem alcançar a paz interior era a renúncia dos seus desejos. Mas também já houve quem visse nos sintomas de Amfortas um verdadeiro quadro clínico de sífilis, a que não faltam as inúmeras referências à chaga que não cicatriza e às dores que se intensificam durante a noite [3]. Para este diagnóstico também contribui a cena em que Kundry, extenuada e pesarosa, chega repentinamente de uma longa viagem às arábias, de onde traz um bálsamo que diz apaziguar o padecimento de Amfortas. É interessante reparar na origem geográfica deste bálsamo, dado a história da medicina nos contar que os árabes foram os primeiros a usar unguentos de mercúrio no tratamento de doenças da pele. Por sua vez, os compostos de mercúrio foram utilizados pelos europeus desde o século XVI até ao início do século XX para tratamento da sífilis. Em 1910 surgiu no mercado o Salvarsan, um fármaco à base de arsénio desenvolvido pelo alemão Paul Ehrlich. Curiosamente, só em 2005 se ficou a conhecer a verdadeira composição deste medicamento, tratando-se afinal de uma mistura de duas substâncias (Figura 13).

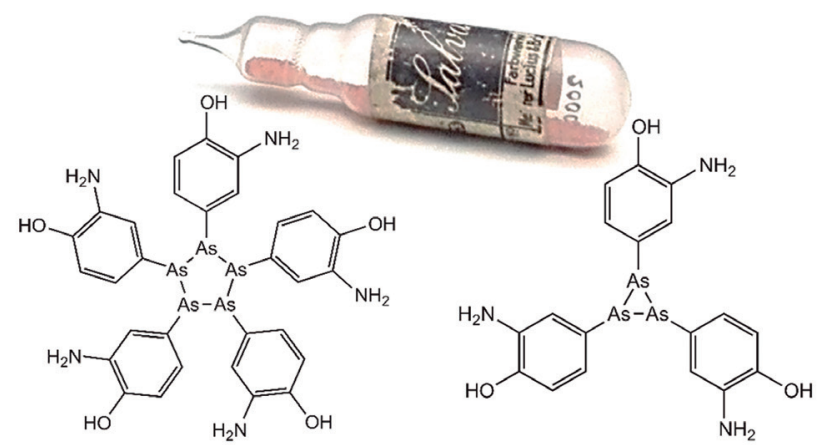

Figura 13 - Estruturas moleculares dos dois compostos constituintes do Salvarsan.

Nesta nova conjuntura terapêutica, a sífilis aparece finalmente de forma desvelada na ópera Lulu (1937) de Alban Berg. Lulu, que no I ato é a mulher de um professor de medicina, no final é uma prostituta nas ruas de Londres, encontrando-se infetada com a espiroqueta. Esta doença surge também em The Rake's Progress (1951) de Igor Stravinsky, estreada quando havia já oito anos que eram conhecidos os primeiros casos de cura por ação da penicilina (Figura 14). No último ato desta ópera, o protagonista, Tom Rakewell, já na terceira fase da doença, encontra-se demente num hospício (Figura 15). Anos antes trocara a província por Londres, e a noiva, Anne Trulove, pelos bordéis da capital.<smiles>CC1(C)S[C@@H]2[C@H](NC(=O)Cc3ccccc3)C(=O)N2[C@H]1C(=O)O</smiles>

Figura 14 - Estrutura molecular da penicilina.

O dealbar do século XX foi um dos períodos mais fascinantes da história da ciência e da medicina, com consequências que se estenderam a domínios como a arte. Por influência da psicanálise, a mente e os seus estados voltaram a marcar presença na ópera (não nos esqueçamos que A Interpretação dos Sonhos de Sigmund Freud fora publicada em 1899!). Tal ocorreu sobretudo pela via da metáfora, recorrendo-se aos grandes mitos e tragédias da Antiguidade. Destaque-se Elektra (1909), de Richard Strauss, e Oedipux Rex (1927), de Igor Stravinsky. 


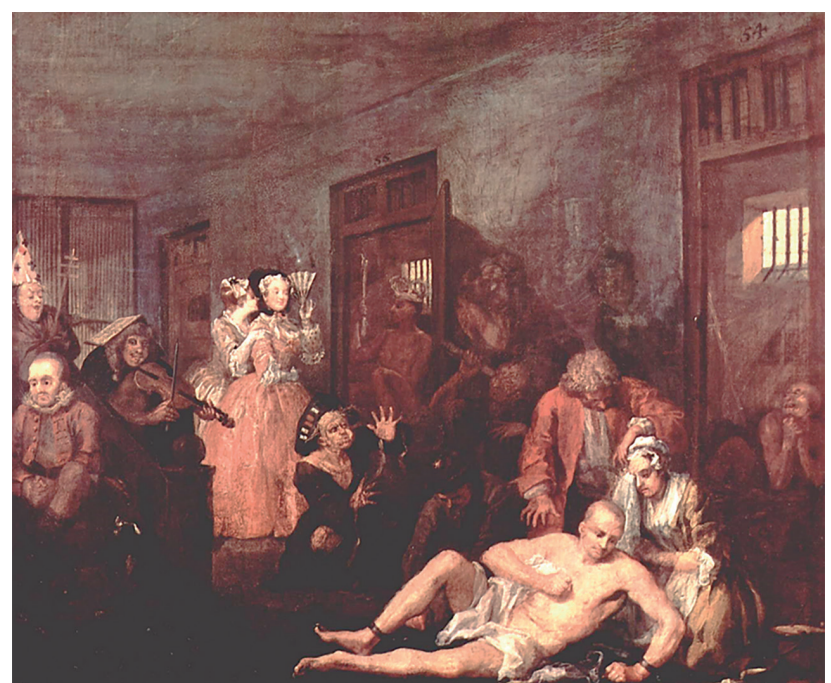

Figura 15 - Oitava pintura da série A Rake's Progress, de William Hogarth (1734). Tom Rakewell, na última fase da sífilis, termina os seus dias no Bedlam, o hospital psiquiátrico de Londres.

Entretanto, em 1922, Alban Berg terminou a partitura de Wozzeck, obra pioneira da atonalidade musical no palco operático, fortemente marcada pelos horrores da I Grande Guerra (Figura 16). Será importante referir que quando esta ópera estreou, em Berlim, em 1925, a medicina convencional via-se confrontada com a emergência da naturopatia e uma forte aversão pelas experiências científicas com seres humanos. Isso é ilustrado pelos tratamentos bizarros que o médico aplica ao pobre Wozzeck, como que fazendo prever os horrores da medicina do regime nazi, alguns anos mais tarde. Nesta obra encontramos um novo olhar sobre a demência: a insanidade de Wozzeck já não é encarada como a libertação para um mundo melhor, é

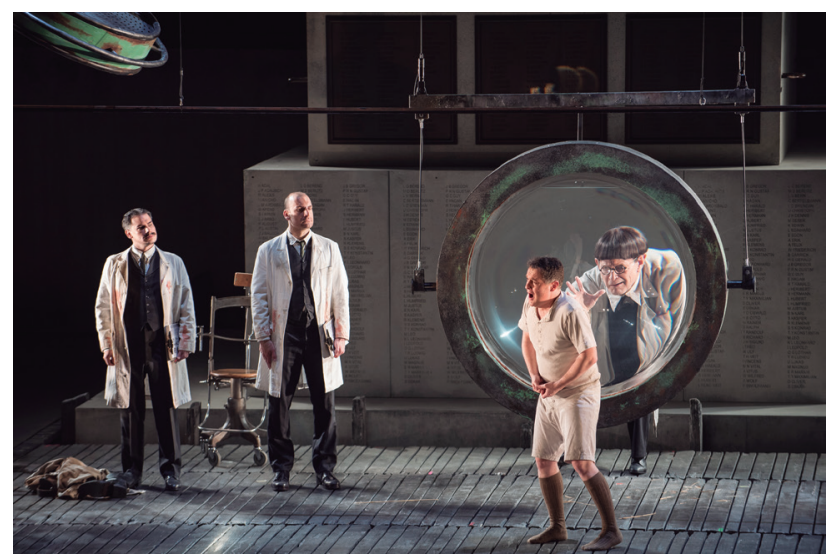

Figura 16 - Wozzeck (Grand Théâtre Genève, 2017). antes vista como uma descida ao inferno. A esse respeito, há uns anos atrás foi extremamente bem conseguido o slogan publicitário de uma produção inglesa desta ópera, ao anunciar: "Wozzeck: uma vida de pesadelo, com um elenco de sonho” (!)

Por fim, uma breve referência a um dos males que mais afligem a Humanidade, o cancro, algo que na ópera é retratado de forma bem realista pela figura de Madame de Croisy, a madre superiora do convento, na emocionante obra de Francis Poulenc Dialogues des Carmélites (1957). O VIH/SIDA, por seu turno, surge em Rent (1994), uma obra do teatro musical da autoria de Jonathan Larson cuja ação, inspirada na ópera La bohème, decorre em Nova Iorque nos anos 80 do século passado. Entretanto, a Ópera de Filadélfia estreou em setembro de 2018 Sky on Swings, uma ópera de Lembit Beecher em que as duas protagonistas sofrem de doença de Alzheimer.

\section{Coda}

É um facto que a formação académica em medicina ocorreu já tardiamente para as mulheres, algo que todavia não aconteceu na ópera, pois em 1758, em L'île de Merlin, de Gluck, já era possível encontrar uma mulher médica, de seu nome Hippocratine. Esclareça-se que esta obra se baseou numa comédia de vaudeville, passada num reino em que tudo e todos eram o inverso daquilo que podia ser encontrado em Paris.

Outra ópera que deverá ainda ser mencionada é Suor Angelica (1918) de Puccini, cuja ação, no século XVII, tem como protagonista Angelica, uma freira que trata das indisposições e doenças das companheiras de convento, recorrendo às plantas medicinais. Com a referência a esta obra colmata-se uma lacuna desta apresentação que não mencionara ainda as enfermeiras e os enfermeiros (que, em boa verdade, têm uma expressão pouco visível no palco lírico).

Embora o retrato operático dos profissionais de saúde seja por vezes bastante mordaz, não deixa de ser interessante reparar como decorrem os últimos momentos de vida das vítimas de tuberculose pulmonar, em função de terem, ou não, um médico junto a si. A presença deste é bem ilustrada, por exemplo, em La traviata: o Dr. Grenvil está junto ao leito de morte de Violetta. Já Mimì, em La bohème, fina-se sem ter tido um médico à sua beira. Veja-se o resultado: na gravação de La bohème de Puccini dirigida por Thomas Beecham (Figura 17), a Mimì de Victoria de los Angeles demora 19 minutos a morrer, enquanto que na gravação da La bohème de Ruggiero
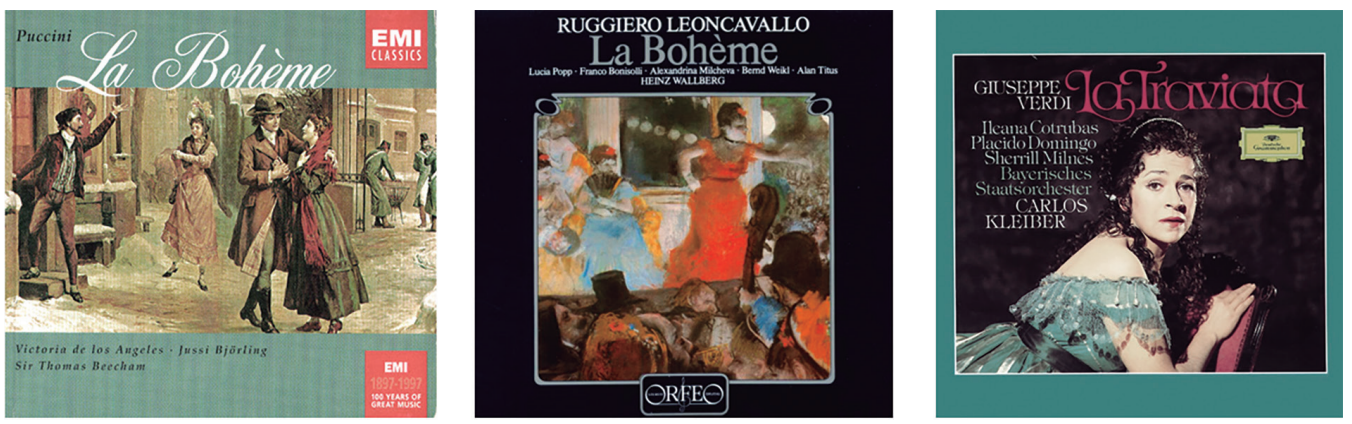

Figura 17 - Capas de gravações comerciais de La bohème de Puccini, La bohème de Leoncavallo e La traviata de Verdi. 
Leoncavallo dirigida por Heinz Wallberg, a morte da mesma personagem (interpretada por Lucia Popp) ocorre em apenas 14 minutos. Já na La traviata dirigida por Carlos Kleiber, a Violetta de Ileana Cotrubas só socumbe ao fim de 25 minutos. Será caso para dizer que, mesmo descontando os tempi do maestro, vale sempre a pena ter um médico por perto!

\section{Referências}

[1] J.B. Soriano, Chest 154 (2018) 409-415.

[2] L.G. Dauber, Am. J. Cardiol. 70 (1992) 838-840.
[3] L. Hutcheon, M. Hutcheon, Opera: Desire, Disease, Death, University of Nebraska Press, Lincoln, 1999

\section{Bibliografia suplementar}

- J.P. André, Poções e Paixões - Química e Ópera, Gradiva, Lisboa, 2018

- J.P. André, J. Chem. Educ. 92 (2015) 66-73.

- A. Palma-Carlos, Os Médicos, a Ópera e a História, Alêtheia, Gaeiras, 2018

- J.I.S. Robertson, Doctors in Opera: An Irreverent Look at Operatic Medicine, Scottish Opera, 2012

- S.N. Willich, British Med. J. 333 (2006) 1333-1335.

\section{Atualidades Científicas}

\section{Catalisadores de Ru suportados para hidrogenação de nitrilos}

As aminas representam uma classe essencial de compostos na indústria química pesada e fina. Os métodos mais comuns para a produção catalítica de aminas incluem a aminação de álcoois, aminação redutiva e a redução de amidas e de grupos nitro. A hidrogenação de nitrilos usando hidrogénio molecular oferece uma via alternativa e sustentável à produção de aminas primárias. Os catalisadores heterogéneos são particularmente úteis na indústria, por exemplo na produção de nylon-66, porque são fáceis de separar da mistura reacional e podem ser reutilizados. Catalisadores de Pd, Co, Ni ou Fe têm sido extensivamente estudados para este fim. No entanto, muitos apresentam baixa seletividade e, por vezes, necessitam de condições reacionais adversas. Por outro lado, tem havido um interesse crescente em desenvolver catalisadores homogéneos altamente seletivos para a redução de nitrilos que utilizem condições reacionais mais suaves. Por exemplo, complexos de Ru contendo ligandos tridentados, nomeadamente Triphos, têm mostrado resultados promissores. Assim, têm sido feitos esforços para a utilização destes catalisadores em meios suportados para utilização em meio heterogéneo.

Paul Kamer, do Instituto de Leibniz para Catálise, da Universidade de Rostock, Alemanha, e colegas desenvolveram um protocolo para imobilização de ligandos do tipo Triphos numa resina de poliestireno. Os ligandos imobilizados resultantes formam complexos de ruténio quando tratados com $\left[\mathrm{Ru}(\mathrm{H})(\mathrm{Cl})\left(\mathrm{PPh}_{3}\right)_{3} \mathrm{CO}\right]$. Os complexos suportados foram usados como catalisadores heterogéneos para a hidrogenação de nitrilos em condições suaves e com elevada seletividade. Além disso, foi demonstrada a aplicabilidade de um catalisador num processo de fluxo contínuo sem perda significativa de desempenho por, pelo menos, 195 horas. A abordagem usada abre o caminho para a síntese automatizada de grandes bibliotecas de ligandos permitindo um design aperfeiçoado de catalisadores que permitam transformações com alta seletividade.

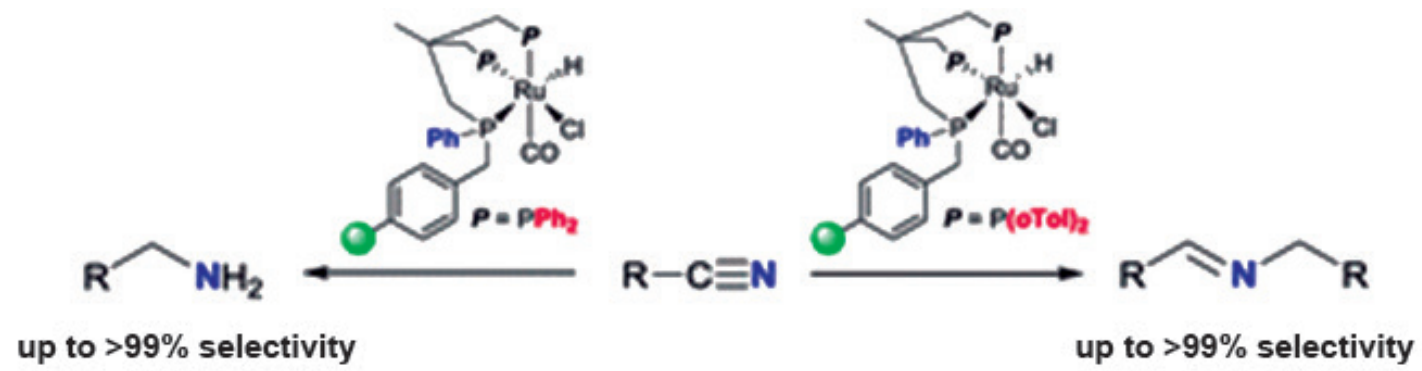

\section{Fonte:}

Supported Ru catalysts for the flow synthesis of amines, https://www.chemistryviews.org/details/news/11172409/Supported_Ru_Catalysts_for_the_Flow_Synthesis_of_Amines.html (Acedido em 10/08/2019)

P. Kamer, R. Konrath, F. Heutz, N. Steinfeldt, N. Rockstroh, Chem. Sci. (2019). DOI: 10.1039/c9sc01415b.

Paulo Mendes

(pjgm@uevora.pt) 